\title{
Coherence, Alignment and Integration: Understanding the Legal Relationship Between Sustainable Development, Climate Change Adaptation and Disaster Risk Reduction
}

\section{Dug Cubie and Tommaso Natoli}

\section{Introduction}

International law can play an important role in promoting national, regional and international actions to tackle the human impacts of climate change and disasters. Of note, 2015 saw the adoption of three interconnected normative frameworks: the Sendai Framework for Disaster Risk Reduction 2015-2030, the Paris Agreement under the UN Framework Convention on Climate Change (UNFCCC), and the UN's 2030 Agenda for Sustainable Development and the Sustainable Development Goals (SDGs). This was no small achievement, as the different evolutionary pathways and siloed nature of these topics had meant that they had remained 'stubbornly separate' up until that point (Melamed et al.,

D. Cubie $(\bowtie) \cdot$ T. Natoli

School of Law, University College Cork, Cork, Ireland

e-mail: d.cubie@ucc.ie; tommaso.natoli@ifrc.org 
2012). ${ }^{1}$ The UN's 2030 Agenda was constructed as the centrepiece of global efforts to eradicate poverty and its stated aim is to provide an allencompassing approach to sustainable development in all its dimensions (economic, social and environmental). In addition to reiterating the importance of full respect for international law and human rights, the Agenda reaffirms the interrelated nature of international commitments made by states and the challenges that they face, while simultaneously highlighting the need for 'integrated solutions'. (UNGA, 2015, paras. 10-13).

One may therefore be tempted to view this body of international norms, rules and standards as a comprehensive and unified system. To an extent, this is correct, with states and the various components of the United Nations system $^{2}$ proposing, debating, interpreting and implementing a multitude of international instruments and institutional arrangements. However, conversely, the range of actors and thematic areas of international regulation has grown exponentially since 1945 , leading to a real risk of overlap, gaps and siloed regimes. The increasing complexity and specialisation of different legal regimes have consequently led to concerns regarding a confusing fragmentation of international law (Koskenniemi, 2007; Peters, 2017; Young, 2012). The problem from a legal perspective, as set out in a key report from the International Law Commission, is that:

such specialized law-making and institution-building tends to take place with relative ignorance of legislative and institutional activities in the adjoining fields and of the general principles and practices of international law. The result is conflicts between rules or rule-systems, deviating institutional practices and, possibly, the loss of an overall perspective on the law. (UNGA, 2006, para. 8)

The counterbalance to this fragmentation is set out in Article 31(3)(c) of the Vienna Convention on the Law of Treaties which requires that 'any relevant rules of international law applicable in the relations between the parties' are considered during the interpretation of a specific treaty. This

\footnotetext{
${ }^{1}$ As discussed further below, the 2012 Outcome Statement from the Rio+20 World Summit provided one of the first strong calls by states for greater connections to be made between these frameworks as they were being developed.

${ }^{2}$ Including the General Assembly, Security Council, International Court of Justice, and the Economic and Social Council. For an overview, see: https://www.un.org/en/about-un/
} 
'systemic integration' of competing international legal obligations was introduced so as to avoid contradictions between different international instruments (McLachlan, 2005). While this integrative imperative applies to conflicting binding international norms, to resolve contradictory articles in two different international treaties, however, questions remain as to the role played by internationally adopted non-binding norms or instruments (so-called 'soft law') and whether one can even talk of systemic integration between binding and non-binding texts. For example, while the UNFCCC and Paris Agreement are binding international legal instruments, ${ }^{3}$ both the Sendai Framework and the SDGs were adopted as authoritative policy frameworks rather than enforceable legal obligations. So, as we shall see in Sect. Relationship between International Law and Soft Law below, while the close connection in subject matter and required actions between these three instruments is well recognised and highlighted by their partially overlapping goals (Melamed et al., 2012; Natoli, 2019), the legal relationship between them is far from clear. The challenge becomes even more acute when one reviews the language used in these different documents. There are references to the need for 'integrated approaches,' 'policy coherence,' 'policy integration' and 'stronger interlinkages,' yet these phrases appear to be used interchangeably and nowhere are they properly defined (Natoli, 2020b).

Despite this legal indeterminacy, the normative impact that social structures and institutions have on hazard prevention, preparation and response is undeniable (de Leon \& Pittock, 2017). ${ }^{4}$ Therefore, our analysis draws on insights from disaster risk management theory and practice. As argued by Albis, Lauta and Raju: 'Disasters ... have social roots. Thus the management of disasters today is dependent on the organisation of society, and hence on our ability to integrate relevant knowledge into the institutional arrangements and policies that underpin our ability to address disaster risk' (Albis et al., 2020). Multi-level understanding and sharing of knowledge regarding the organisation of legal and policy

\footnotetext{
${ }^{3}$ While the Paris Agreement is an international treaty which contains legal obligations for state parties, the enforceability of these obligations has been questioned: Daniel Bodansky, 'The Legal Character of the Paris Agreement' (2016) 25(2) Review of European, Comparative and International Environmental Law 142-150.

${ }^{4}$ For general discussion of the social function of law: Philip Allott, 'The Concept of International Law' (1999) 10 European Journal of International Law 31-50.
} 
frameworks can therefore assist in promoting connected thinking and the destruction of disciplinary silos. ${ }^{5}$

As with other contributions in this book, a key theme running throughout this chapter is the need to understand specific aspects of the relationship between sustainable development, climate change adaptation (CCA) and disaster risk reduction (DRR). From our legal perspective, we hope to provide an overview of the interactions between legal and policy frameworks at the international, regional and national levels, while drawing on empirical observations of the law in practice. The chapter commences with discussion of the legal status of different international instruments, before providing a textual analysis of the language used by states, the UN and other actors in the relevant documents. We then propose an 'hourglass' model of the legal relationships between the different frameworks for sustainable development, CCA and DRR based on: (a) systemic coherence at the international level; (b) vertical alignment between the international, regional and national levels; and (c) horizontal integration of international norms at the domestic level.

\section{Methodology}

As noted by Christopher McCrudden, a key form of academic legal research is that which focuses on the understanding and internal coherence of legal concepts and legal reasoning. McCrudden highlights that this type of research addresses questions such as 'how legal concepts fit together, the consistence of the use of concepts in different areas of law,

\footnotetext{
${ }^{5}$ While existing synergies and potential solutions to overcome the siloed nature of these frameworks have been examined in several previous research and technical analysis, our analysis focuses specifically on the content of respective legal instruments and the need for linguistic clarity. Examples of other relevant papers include: Lisa Schipper \& Mark Pelling, 'Disaster Risk, Climate Change and International Development: Scope for, and challenges to, integration' (2006) 30/1 Disasters, 19-38; Tom Mitchell, Maarten van Aalst \& Paula Silvia Villanueva, 'Assessing Progress on Integrating Disaster Risk Reduction and Climate Change Adaptation' in Development Processes, Strengthening Climate Resilience Discussion Paper 2 (2010); Ilan Kelman, 'Linking Disaster Risk Reduction, Climate Change, and the Sustainable Development Goals' (2017) 26/3 Disaster Prevention and Management; UN FCCC/TP/2017/3, 'Opportunities and Options for Integrating Climate Change Adaptation with the Sustainable Development Goals and the Sendai Framework for Disaster Risk Reduction 2015-2030', Technical paper by the Secretariat (2017).
} 
[and] the extent to which general principles can be extracted from legal reasoning that can be used to predict or guide future legal decisionmaking' (McCrudden, 2006, p. 632). In researching the coherence of the international normative frameworks addressing sustainable development, CCA and DRR, we have utilised a doctrinal legal analysis, namely a textual analysis of the relevant international instruments.

However, doctrinal legal analysis also requires an understanding of how the law works in practice (Ibid., p. 633), so this chapter also draws on empirical research undertaken in the Pacific Island Countries (PICs) by Dr Natoli through the IRC-MSCA CAROLINE project, 'Leave No One Behind: Developing Climate-Smart/Disaster Risk Management Laws that Protect People in Vulnerable Situations for a Comprehensive Implementation of the UN Agenda 2030.'

\section{Results and Discussion}

\section{Sources and Enforcement of International Law}

In domestic legal systems, to understand whether a particular action or omission is required by law, one must first identify whether there is a binding and enforceable rule regulating particular behaviour. For example, in some countries a pedestrian crossing a road on a red light might be committing a criminal or administrative offence, while in others jaywalking may not be prohibited by law and is viewed simply as a risk that the individual takes upon themselves. To find out what the law is, you need to examine the sources of law for that particular country, such as legislation, case law, administrative orders, etc. There are likewise rules setting out the sources of international law. For an international lawyer, the first point of reference is Article 38(1) of the Statute of the International Court of Justice (ICJ), which sets out four sources upon which the ICJ can rely, namely: (a) international conventions; (b) international custom; (c) general principles of law; and (d) judicial decisions and highly

\footnotetext{
${ }^{6}$ For more details on the project, see: https://media.ifrc.org/ifrc/what-we-do/disaster-law/ leave-no-one-behind/
} 
qualified publications as a subsidiary means of determination (Wolfrum, 2011). The binding legal status of international conventions, such as the UN Framework Convention on Climate Change, is therefore fairly clear. The challenges arise when one starts examining other internationally authoritative texts, which may or may not have the force of international law. For example, UN General Assembly Resolutions are generally held not to have the force of international law but may influence the behaviour of states, which in turn might come to be recognised as binding international custom. ${ }^{7}$ The most famous example is the Universal Declaration of Human Rights which was initially adopted as a General Assembly Resolution on 8th December 1948 but has subsequently been recognised as binding on all states via customary international law (Hannum, 1996). Other influential texts can include recommendations adopted by international conferences, decisions by international organisations and even guidelines or plans of action developed by nongovernmental actors, academics or practitioners (Blutman, 2010, pp. 607-608).

This broad range of authoritative but non-binding sources (at both the domestic and international levels) is often called 'soft law.' Debate rages regarding this apparent misnomer - for how can something be 'law' if it is not legally enforceable? ${ }^{8}$ While it is outwith the scope of this chapter to engage in depth with this debate, it is nonetheless of direct relevance as two of the three frameworks under consideration, namely the Sendai Framework and the SDGs, fall squarely within the soft law definition (Siders, 2016). Moreover, within the purview of all three frameworks are a series of important non-binding guidance documents, such as the Cancún Adaptation Framework adopted by the UNFCCC Conference of the Parties (CoP16) in 2011. ' Both the Sendai Framework and the SDGs were adopted at global diplomatic conferences, following extensive

\footnotetext{
${ }^{7}$ UN General Assembly Resolutions can also, in certain cases, be accepted as "highly qualified publications" under Article 38(1)(d), i.e. as opinio juris.

${ }^{8}$ For differing perspectives, see: Jean d'Aspremont, 'Softness in International Law: A Self-Serving Quest for New Legal Materials' (2008) 19(5) European Journal of International Law 1075-1093; Arnold N. Pronto, 'Understanding the Hard/Soft Distinction in International Law' (2015) 48 Vanderbilt Journal of Transnational Law 941-956.

${ }^{9}$ The Conference of the Parties mechanism was established by Article 7 of the UNFCCC as the "supreme body of this Convention."
} 
state and non-state actor engagement, and so represent authoritative statements of policy, although not of law. ${ }^{10}$ This in turn raises questions as to their legal relationship with the UNFCCC and Paris Agreement, which contain binding international legal obligations.

\section{Relationship Between International Law and Soft Law}

As noted in the Introduction, while the risk of fragmentation of international legal regimes is well recognised, the legal requirement of systemic integration set out in the Vienna Convention on the Law of Treaties only applies to binding international law - in other words, sources of international law corresponding to Article 38(1) of the ICJ Statute, but not soft law sources. ${ }^{11}$ It is therefore difficult to talk of 'systemic integration' in the strictly legal sense in regard to the frameworks for CCA, DRR and the SDGs. Yet, it has long been recognised that soft law sources may have normative impact - as far back as 1980, Richard Baxter, while serving as a judge on the ICJ, argued that: 'I intend to use the term ['international agreements'] in a much wider sense as comprehending all those norms of conduct which States or persons acting on behalf of States have subscribed to, without regard to their being binding, or enforceable, or subject to an obligation of performance in good faith' (Baxter, 1980, p. 550). Baxter continues by developing the concept of 'political treaties' which are 'merely joint statements of policy' (Ibid., p. 551). Using this analogy, states cannot 'violate' the Sendai Framework or SDGs, or indeed the Cancún Adaptation Framework, and so there is no legal recourse to enforce states' compliance. ${ }^{12}$

\footnotetext{
${ }^{10}$ For analysis of the legal status of the Hyogo Framework for Action, precursor to the Sendai Framework, see: Luca Corredig, 'Effectiveness and Accountability of Disaster Risk Reduction Practices: An Analysis through the Lens of IN-LAW' in: Ayelet Berman et al (eds.), Informal International Lawmaking: Case Studies (Torkel Opsahl Academic EPublisher, 2012).

${ }^{11}$ Koskenniemi is clear that Art 31(3)(c) VCLT only refers to 'rules of international law' and so "thus emphasising that the reference for interpretation purposes must be to rules of law, and not to broader principles or considerations which may not be firmly established as rules." UNGA, 2006, para. 426.

${ }^{12}$ This 'informality' in international law-making is not unique, as was extensively documented by the 'IN-LAW' project: Joost Pauwelyn, Ramses A. Wessel and Jan Wouters (eds.), Informal
} 
Yet, if soft law texts cannot be enforced, what is the legal relationship between a binding source of international law such as the Paris Agreement and non-binding texts such as the Sendai Framework and the SDGs? At the simplest level, there is no relationship, since a breach of the Paris Agreement by a state party would need to be adjudicated solely based on the legal obligations set out within the UNFCCC framework. ${ }^{13}$ Conversely, it is not possible for a state to legally violate a non-binding policy document such as the Sendai Framework or the SDGs, so no legal consequences flow from it and it would therefore not trigger that state's legal obligations in a separate binding text such as the Paris Agreement.

However, when one examines the language used by states in these legal and policy frameworks, it is clear that they have acknowledged the close connections between their substantive content and objectives. The Preamble to the UNFCCC, adopted in 1992, specifically notes that: 'Responses to climate change should be coordinated with social and economic development in an integrated manner.' ${ }^{14}$ More recently, the final Outcome Statement of the Rio+20 World Summit in 2012 was a key intergovernmental acknowledgement of the need to move away from a fragmented and siloed approach. In particular, at the Rio+20 summit, heads of state called for: 'disaster risk reduction and the building of resilience to disasters to be addressed with a renewed sense of urgency in the context of sustainable development and poverty eradication and, as appropriate, to be integrated into policies, plans, programmes and budgets at all levels' (UNGA, 2012, para. 186). Moreover, the Outcome Statement continued to stress:

the importance of stronger interlinkages among disaster risk reduction, recovery and long-term development planning, and call for more coordinated and comprehensive strategies that integrate disaster risk reduction and climate change adaptation considerations into public and private investment, decision-making and the planning of humanitarian and devel-

International Lawmaking (Oxford University Press, 2012); and Berman et al, Informal International Lawmaking (n.10).

${ }^{13}$ Article 14 UNFCCC sets out the mechanisms for the settlement of disputes between state parties to the Convention, namely negotiation, arbitration or submission to the International Court of Justice.

${ }^{14}$ Preamble, UNFCCC. 
opment actions, in order to reduce risk, increase resilience and provide a smoother transition between relief, recovery and development. (Ibid., para. 188)

This requirement was solidified three years later when the UN 2030 Agenda reaffirmed 'the outcomes of all major United Nations conferences and summits which have laid a solid foundation for sustainable development and helped to shape the new Agenda.' (UNGA, 2015, para. 11). Yet, a semantic examination of the relevant documents shows that key terminology is used in an inconsistent manner. The final section of this chapter will therefore attempt to rationalise the plethora of phrases used to describe the linkages and relationship between these three legal and policy frameworks into a clear structure based on 'coherence,' 'alignment' and 'integration'. Considering the diversity of national and regional contexts, this should not be seen as a one-size-fits-all formula but hopefully will provide an overarching mechanism for understanding the (legal) relationships between the three topics.

\section{The 'Hourglass' Model: Coherence, Alignment and Integration}

Certain words and phrases have a specific legal definition or understanding, both at the domestic level and in international law. So, for example, the 'principle of integration' in international environmental law ${ }^{15}$ relates to a legal obligation on the part of states to integrate environmental considerations into the planning and implementation of development activities (McIntyre, 2013). Yet, as noted by McIntyre, even within the EU's advanced regional legal system the precise normative character and substantive content of the principle are far from clear (Ibid., p. 105). In a similar manner, the extensive recourse to the concept of 'resilience' in the Sendai Framework, Paris Agreement and 2030 Agenda means that one can view it as a 'semantic cement' holding the three frameworks together. However, there has been valid criticism of the differential understandings of the way the

\footnotetext{
${ }^{15}$ It should be noted that international environmental law, which encompasses issues such as biodiversity and pollution, is not synonymous with climate change law.
} 
concept is employed across the three instruments (Siders, 2016, pp. 114-120). Therefore, for the purposes of this analysis and reflecting the uncertain legal relationships between the different texts under consideration, we will utilise standard dictionary definitions of the relevant words rather than relying upon specific legal definitions.

Due to the multidimensional relationships between the three frameworks at the international, regional and national levels, we will commence with a discussion of systemic coherence at the international level (a), followed by vertical alignment between the international, regional and national/sub-national levels (b), and finally horizontal integration at the domestic level (c). As set out in Fig. 3.1 below, the dynamic nature of these relationships can be visualised in a unified model represented by the classic image of an hourglass.

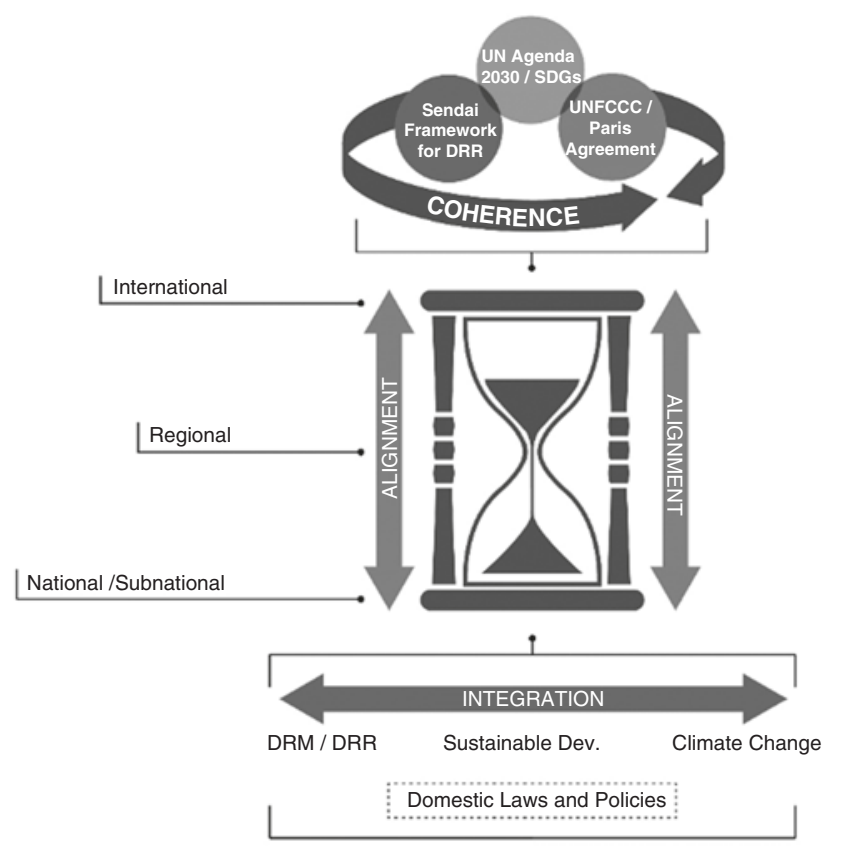

The hourglass can also be turned upside down, thereby describing how "normative inputs" provided by States can be uploaded and consolidated through intergovernmental processes at both regional and global levels.

Fig. 3.1 Hourglass model 


\section{Systemic Coherence: The Need for Consistency}

Starting from the consideration that 'coherence' is defined as any 'logical and consistent' argument or theory (Soanes \& Stevenson, 2006, p. 278), ensuring the effective coexistence of the three global frameworks analysed in this study is facilitated by the extent to which they share the same principles/criteria in their respective normative reasoning and purposes (i.e. logic) and exert a simultaneous regulatory effect without discrepancies and in compatible forms (i.e. consistency). ${ }^{16}$ Both 'logic' and 'consistency' elements are detectable in the text of the three instruments, albeit in different forms.

The 2030 Agenda /SDGs is the framework where the two elements emerge most vividly. Described as 'universal' in nature and based on the idea of a 'collective journey', one can consider 'coherence' as one of the Agenda's inherent features, as demonstrated by the recurrent use of this term throughout the document. The Agenda's overarching purpose of unifying the multifaceted dimensions of sustainability entails humanity living 'in harmony with nature' (para. 9), while also being able to cope with the adverse impacts of climate change (para. 14) and related disaster risks (para. 33). This idea is enshrined in the wording of the SDGs, such as Goal 1.5 ('[B]uild the resilience of the poor and those in vulnerable situations and reduce their exposure and vulnerability to climate-related extreme events') and Goal 13.1 ('Strengthen resilience and adaptive capacity to climate-related hazards and natural disasters in all countries'). With the clear intention to prevent overlaps or conflicts, the Agenda includes two 'coherence clauses' - the first recognising the UNFCCC is the 'primary international, intergovernmental forum for negotiating the global response to climate change' (para. 31, plus SDG 13) and the second clarifying that cities and human settlements should develop and implement holistic disaster risk management at all levels 'in line with the Sendai Framework for Disaster Risk Reduction 2015-2030' (SDG 11.b).

Likewise, by acknowledging climate change as a key source of disaster risk and a serious impediment to sustainable development, the various intergovernmental negotiations of 2015 were recognised in the Sendai

\footnotetext{
${ }^{16}$ For discussion of coherence across the three frameworks, see: Siders, 2016.
} 
Framework as a 'unique opportunity to enhance coherence' across interrelated processes, while 'respecting' the role of the UNFCCC 'within its mandate'. ${ }^{17}$ It is no surprise, therefore, that the Sendai Framework's guiding principles and priorities openly recognise the need for coherence across the SDG, CCA and DRR agendas in the development and implementation of all relevant policies, plans, practices and mechanisms. ${ }^{18}$

A similar aim can be detected in the Paris Agreement, although through more cautiously diplomatic language. Both the Preamble and certain operative provisions include elements highlighting the intrinsic relationship between climate change, risk reduction and sustainable development - not least the prominent placement of the official acknowledgement of the UN 2030 Agenda and SDG Goal 13 in particular, and the Sendai Framework on the first page of the Agreement. This is followed by Article 2(1) which states that among the Agreement's objectives is the consolidation of 'the global response to the threat of climate change, in the context of sustainable development', including by '[i]ncreasing the ability to adapt to the adverse impacts of climate change and foster climate resilience.' This objective is bolstered by Article 7(1) establishing a 'global goal on adaptation' which entails 'enhancing adaptive capacity, strengthening resilience and reducing vulnerability to climate change, with a view to contributing to sustainable development and ensuring an adequate adaptation response.' Furthermore, in the context of a state's nationally determined contributions, Article 6(8) notes 'the importance of integrated, holistic and balanced non-market approaches' and continues by stating that such approaches shall aim to '... (c) Enable opportunities for coordination across instruments and relevant institutional arrangements.' These provisions clearly aim to highlight the cross-cutting relationship between a state's adaptive capacity, climate resilience and sustainable development objectives. However, while the promotion of coherence between the three legal and policy frameworks is a worthwhile goal by

\footnotetext{
${ }^{17}$ Sendai Framework, paras. 4, 6, 11 and 13.

${ }^{18}$ See paras. 19(h), 28(b), 31(a), 48(c) and 49. See also para.50, addressing the intention to develop a mechanism to measure global progress in the implementation of the Sendai Framework in conjunction with the work of the Inter-Agency and Expert Group on Sustainable Development Goal Indicators.
} 
itself, it is insufficient. Therefore, we next turn to the processes whereby international normative instruments can influence regional and national approaches, and vice versa.

\section{Vertical Alignment: From International to National/ Sub-National (and Back)}

Having discussed how the three frameworks are horizontally interlinked at the international level, we will now consider them through the lens of multilevel governance, namely the vertical relationship between global, regional/sub-regional and national/sub-national decision-making bodies and institutions (Lane \& Hesselman, 2017). While the three frameworks under consideration do not explicitly refer to it, the concept of normative 'alignment' appears as particularly fit-for-purpose, considering that the verb 'align' defines any act of placing or arranging items 'in a straight line or into correct relative positions' (Soanes \& Stevenson, 2006, p. 33.).

There are a wide variety of differing institutional and legal approaches adopted by regional organisations, and the hourglass model recognises that regional structures and initiatives may act as a central fulcrum to facilitate the two-way flow of knowledge, experience and norms between the national and international levels. For instance, interesting and up-todate findings on vertical alignment in climate-risk governance can be found by exploring relevant practice within the Pacific Island region which hosts five of the ten most at-risk countries in the world and is where climate change is causing serious consequences at a growing rate (IFRC, 2020). Over the last few years, many Pacific Island Countries (PICs) have been reforming their institutional and normative systems in order to pursue a holistic approach to disaster and climate resilience, and this process has been closely tied to the regional and international advancements from 2015 onwards (Hopkins, 2019). For example, the Government of Fiji has undertaken detailed analysis of how to align their domestic adaptation policies with the Sendai Framework and the SDGs. So, when launching their National Adaptation Plan in 2018, the Fijian Government noted: 'This NAP has been aligned to support these international 
agreements as one of many national processes through which these agreements should be achieved'(Republic of Fiji, 2018, p. 37; Natoli, 2020a).

A critical role in this alignment process has been played by regional organisations such as the Pacific Community (SPC), the Secretariat of the Pacific Regional Environment Programme (SPREP) and the Pacific Islands Forum Secretariat (PIFS). These organisations have supported and channelled national efforts to build common positions, promoting the most relevant initiatives and providing the necessary technical expertise. A key outcome of this dynamic is the 'Framework for Resilient Development in the Pacific (FRDP)', a high-level strategic document adopted in 2016 to guide different stakeholder groups on how to enhance resilience to climate change and disasters, 'in ways that contribute to and are embedded in sustainable development' (SPC et al., 2016).

The FRDP drafting process incorporated the contribution of global bodies such as the UN Development Programme (UNDP) and UN Office for Disaster Risk Reduction (UNDRR). It is not surprising, then, that a clear link with the three instruments of reference is evident throughout the text, where the intention to contribute to and complement their implementation is repeatedly stated (SPC et al., 2016, pp. 3, 5, 10-11). This also provides evidence of PICs' intention to opt for a coordinated regional implementation of the Post-2015 Agenda on climate-risk governance and feed into global intergovernmental processes with 'a single voice'.

Of note, the FRDP was the result of an '[e]xtensive and inclusive engagement process with stakeholders, from national and communities to regional and international levels' (SPC et al., 2016, p. 1). In light of this, the vertical 'positioning' that inspired the document should not be considered as unidirectional (i.e. only going from the global to the local), as it can also build on the capacity to collect and transmit inputs from communities/civil society to the national, regional and intergovernmental levels. The dynamic nature of this shifting relationship from top-down to bottom-up is represented in the hourglass model proposed here by the simple fact that an hourglass is equally effective whichever way it is turned (see Fig. 3.1). 


\section{Horizontal Integration: Mainstreaming into Domestic Law and Policy}

Following our discussion of systemic coherence at the international level and vertical alignment between the international, regional/sub-regional and national/sub-national levels, the third component of the hourglass model focuses specifically on national law and policy. Considering that the dictionary definition of 'integration' is 'to combine or be combined to form a whole' (Soanes \& Stevenson, 2006, p. 738), it is perhaps surprising that this phrase is used across so many of the documents cited above. It is clear from the fact that the three relevant frameworks were negotiated in separate parallel mechanisms that states did not intend for them to be combined to form a single instrument. However, the word 'integration' is used in a more specific context when discussing the domestic level. For example, SDG Goal 13.2 sets out the need to 'integrate climate change measures into national policies, strategies and planning. ${ }^{19}$ Likewise, the Paris Agreement calls on parties to integrate climate adaptation 'into relevant socioeconomic and environmental policies and actions, where appropriate. ${ }^{20}$ While the Sendai Framework urges states to 'mainstream and integrate disaster risk reduction within and across all sectors' and to address DRR and build resilience to disasters 'with a renewed sense of urgency in the context of sustainable development and poverty eradication and, as appropriate, to be integrated into policies, plans, programmes, and budget at all levels and considered within relevant frameworks' (para. 2).

One can therefore deduce that a key objective of drafters in using the word 'integration' is not to create a single international framework but to encourage states to take a holistic view across all policy areas at the domestic level. The normative reform process currently underway in the Republic of Fiji represents an instructive example of how this perspective can effectively be pursued. A consistent and integrated approach between CCA and DRR can be observed in the relevant policies adopted by the Fijian authorities since 2015, aligning at the same time with regional and

\footnotetext{
${ }^{19}$ SDG 13.2.

${ }^{20}$ Paris 7.5 .
} 
global commitments (Natoli, 2020a, pp. 36-45). As clearly set out in the Fiji National Adaptation Plan (NAP): 'Horizontal integration refers to the mainstreaming of climate change issues into national-level development planning processes so that they are suitably climate-informed' (Republic of Fiji, 2018, p. 46).

From an institutional point of view, a clear example of integration is given by the new National Climate Change Policy (NCCP), which encompasses a careful articulation of Fiji's priorities in reducing present and future climate risks through a 'woven approach' to resilient development (Republic of Fiji, 2019, p. 8). Interestingly, among its main structural reforms are the creation of a Cabinet Committee on Climate and Disaster Risk (CCCDR) and the re-establishment of the National Climate Change Coordination Committee (NCCCC). The updated mandate of the NCCCC includes a requirement to provide '[c]lear guidance for interactions with the National Disaster Management Committee on issues that cross-cut the adaptation and disaster risk reduction objectives to improve the ability to coordinate resources and improve the accuracy of risk reduction reporting and planning' (Republic of Fiji, 2019, pp. 47, 78).

This domestic integration is also reflected in the current text of the Fijian Climate Change Bill, which was published in late 2019. Drafted in close synergy with the NCCP, the Bill aims to integrate the consideration of climate change projections, articulation of risk reduction responsibilities and formulation of resilience-building objectives across all sector plans and strategies. ${ }^{21}$ Once enacted, the Bill is expected to provide the necessary legal basis for establishing clear responsibilities and obligations, so as to ensure overall consistency across governmental structures and promote the harmonisation and integration of the entire normative system. Of note, the judiciary may be called on to play an important role: as per the current draft Bill, the Fijian High Court will be endowed with the power to set aside and order the remake of any specific legislative act that does not adequately take account of climate change. ${ }^{22}$

\footnotetext{
${ }^{21}$ Fiji, Climate Change Bill (Draft) 2019, art.4(f).

${ }^{22}$ Ibid. art.16.
} 


\section{Conclusions}

Just as sand flows from and into either half of an hourglass, the sharing of knowledge and expertise in the fields of CCA, DRR and sustainable development flows from the local to the national, the regional to the international, and back again. This vertical alignment helps to ensure that there is bidirectional exchange of legal principles and operational experience, as well as monitoring of the actions taken at each level. ${ }^{23}$ As Harold Koh has observed, 'Twenty-first century international lawmaking has become a swirling interactive process whereby norms get 'uploaded' from one country into the international system, and then 'downloaded' elsewhere into another country's laws or even a private actor's internal rules' (Koh, 2012). The importance of regional organisations in supporting this interactive process of vertical alignment is evident from the coordinated approach undertaken in the Pacific Region.

However, vertical alignment will be hard to achieve if there is not a coherent body of norms and practice at the international level. Therefore, acknowledging and promoting the shared logic and consistency between the Paris Agreement, Sendai Framework and 2030 Agenda, as well as any inconsistencies, are essential. In other words, while the limited scope of Article 31(1)(c) of the Vienna Convention on the Law of Treaties does not allow us to talk about 'systemic integration' of the post-2015 global agenda on climate-risk governance from a legal perspective, one can identify 'systemic coherence' between the relevant frameworks. Nevertheless, as research from the Pacific region indicates, there is no one-size-fits-all solution to legal and policy integration at the national level. Full integration via the creation of a unitary governmental department or piece of legislation is not necessarily the best option, and each state will need to review their own domestic structures and context. ${ }^{24}$ However, emerging practice is based on the expectation that enhancing integration at the domestic level can reduce duplication and optimise the use of limited

\footnotetext{
${ }^{23}$ Each of the three global frameworks has internal monitoring and reporting mechanisms, which state parties are expected to comply with.

${ }^{24}$ See for instance the Fijian Disaster Risk Reduction Policy 2018-2030 (NDRRP) noting that the degree of integration will "vary based on the needs and priorities" (para. 115).
} 
resources and the sharing of technical expertise, as well as reflect and support coherence at the international level. As a simple visual representation of these processes, the hourglass model aims to promote understanding of the legal relationship between sustainable development, climate change adaptation and disaster risk reduction, and break down the regulatory silos which have hampered effective cross-cutting dialogue and action in the past.

\section{References}

Albis, K., Cedervall Lauta, K., \& Raju, E. (2020). Disaster Knowledge Gaps: Exploring the Interface Between Science and Policy for Disaster Risk Reduction in Europe. International Journal of Disaster Risk Science, 11, 1-12. Baxter, R. R. (1980). International Law in 'Her Infinite Variety'. International and Comparative Law Quarterly, 29, 549-566.

Blutman, L. (2010). In the Trap of a Legal Metaphor: International Soft Law. International and Comparative Law Quarterly, 59, 605-624.

de Leon, E. G., \& Pittock, J. (2017). Integrating Climate Change Adaptation and Climate-Related Disaster Risk-Reduction Policy in Developing Countries: A Case Study in the Philippines. Climate \& Development, 9(5), 471-478.

Hannum, H. (1996). The Status of the Universal Declaration of Human Rights in National and International Law. Georgia Journal of International and Comparative Law, 25, 287-397.

Hopkins, W. J. (2019). Pacific (2018). Yearbook of International Disaster Law, 1, 366-372.

IFRC (International Federation of Red Cross and Red Crescent Societies). (2020). Risk Governance for Resilient Development in the Pacific, Reports from Legislating and Policy Making for Climate Smart DRM Workshop - Fiji, October 2019, 3.

Koh, H. (2012). Twenty-First Century International Lawmaking. Speech at Georgetown University Law Center, Washington, DC (17 October 2012) 14. Koskenniemi, M. (2007). The Fate of Public International Law: Between Technique and Politics. Modern Law Review, 70(1), 1-30.

Lane, L., \& Hesselman, M. (2017). Governing Disasters: Embracing Human Rights in a Multi-Level Multi-Duty Bearer, Disaster Governance Landscape. Politics and Governance, 5(2), 93-104. 
McCrudden, C. (2006). Legal Research and the Social Sciences. Law Quarterly Review, 122, 632-650.

McIntyre, O. (2013). The Principle of Environmental Integration in Sustainable Development Law: Sobering Lessons from EU Law. In L. Western, P. Taylor, \& A. Michelot (Eds.), Confronting Ecological and Economic Collapse: Ecological Integrity for Law, Policy and Human Rights (pp. 104-110). Earthscan/Taylor $\&$ Francis.

McLachlan, C. (2005). The Principle of Systemic Integration and Article 31(3) (c) of the Vienna Convention. International and Comparative Law Quarterly, 54, 279-320.

Melamed, C, Scott, A., \& Mitchell, T. (2012). Separated at Birth, Reunited at Rio? A Roadmap to Bring Environment and Development Back Together (May 2012) Background Note, Overseas Development Institute.

Natoli, T. (2019). Literature Review on Aligning Climate Change Adaptation (CCA) and Disaster Risk Reduction (DRR). IFRC/UCC.

Natoli, T. (2020a). Law and Policies That Protect the Most Vulnerable Against Climate-Related Disaster Risks: Findings and Lessons Learned from Pacific Island Countries. IFRC|UCC.

Natoli, T. (2020b). Compendium on the Post-2015 Global Agenda on ClimateRisk Governance, UCC Centre for Criminal Justice \& Human Rights (CCJHR), Research Projects (May 2020). Available at: https://www.ucc.ie/ en/ccjhr/publications/. Accessed 30 Aug 2021.

Peters, A. (2017). The Refinement of International Law: From Fragmentation to Regime Interaction and Politicization. International Journal of Constitutional Law, 15(3), 671-704.

Republic of Fiji. (2018). National Adaptation Plan: A Pathway Towards Climate Resilience.

Republic of Fiji. (2019). National Climate Change Policy 2018-2030.

Siders, A. (2016). Resilient Incoherence - Seeking Common Language for Climate Change Adaptation, Disaster Risk Reduction, and Sustainable Development. In J. Peel \& D. Fisher (Eds.), The Role of International Environmental Law in Disaster Risk Reduction (pp. 110-112). Brill.

Soanes, C., \& Stevenson, A. (Eds.). (2006). Concise Oxford English Dictionary (11 revised ed.). Oxford University Press.

SPC, SPREP, PIFS, UNDP, UNISDR, \& USP. (2016). Framework for Resilient Development in the Pacific: An Integrated Approach to Address Climate Change and Disaster Risk Management (FRDP) 2017-2030, 4. 
UNGA (United Nations General Assembly). (2006). Fragmentation of International Law: Difficulties Arising from the Diversification and Expansion of International Law. Report of the Study Group of the International Law Commission, Finalized by Martti Koskenniemi, UN Doc: A/CN.4/L.682 (13 April 2006).

UNGA (United Nations General Assembly). (2012). The Future We Want. UN Doc: A/RES/66/288 (11 September 2012).

UNGA (United Nations General Assembly). (2015). Transforming Our World: The 2030 Agenda for Sustainable Development, UN Doc: A/Res/70/1 (21 October 2015).

Wolfrum, R. (2011). Sources of International Law. In R. Wolfrum (ed.), Max Planck Encyclopedia of Public International Law [Online]. Oxford University Press. Available at: https://opil.ouplaw.com/home/mpil. Accessed 30 Aug 2021.

Young, M. A. (Ed.). (2012). Regime Interaction in International Law: Facing Fragmentation. Cambridge University Press.

Open Access This chapter is licensed under the terms of the Creative Commons Attribution 4.0 International License (http://creativecommons.org/licenses/ by/4.0/), which permits use, sharing, adaptation, distribution and reproduction in any medium or format, as long as you give appropriate credit to the original author(s) and the source, provide a link to the Creative Commons licence and indicate if changes were made.

The images or other third party material in this chapter are included in the chapter's Creative Commons licence, unless indicated otherwise in a credit line to the material. If material is not included in the chapter's Creative Commons licence and your intended use is not permitted by statutory regulation or exceeds the permitted use, you will need to obtain permission directly from the copyright holder.

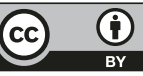

